\title{
PSICOLOGIA POSITIVA E RESILIÊNCIA: O FOCO NO INDIVÍDUO E NA FAMÍLIA
}

\author{
Maria Angela Mattar Yunes ${ }^{*}$
}

\begin{abstract}
RESUMO. O presente artigo apresenta a psicologia positiva como movimento de investigação de aspectos potencialmente saudáveis dos seres humanos, em oposição à psicologia tradicional e sua ênfase nos aspectos psicopatológicos. Dentre os fenômenos indicativos de vida saudável destaca-se a resiliência, por referir-se a processos que explicam a superação de adversidades, cujo discurso hegemônico foca o indivíduo. As pesquisas quantitativas colaboram para naturalizar a resiliência como capacidade humana, e os estudos em famílias trazem contribuições de pesquisas qualitativas realizadas na visão sistêmica, ecológica e de desenvolvimento. Consideradas as dificuldades metodológicas e as controvérsias ideológicas do conceito, sugere-se uma cautelosa investigação de sentido antes da aplicação do termo.
\end{abstract}

Palavras-chave: Psicologia positiva; resiliência; resiliência em famílias.

\section{POSITIVE PSYCHOLOGY AND RESILIENCE: FOCUS ON THE INDIVIDUAL AND FAMILIES}

\begin{abstract}
The present work presents positive psychology as a movement that proposes the investigation of potentially healthy aspects of human beings in opposition to traditional psychology and its emphasis in psychopathology. Among the phenomena that indicate healthy life, resilience is distinguished by its references to processes that explain bouncing back to adversities whose hegemonic discourse is focused on the individual. The quantitative studies have contributed to the naturalization of resilience as a human capacity, and the family studies were identified as based on qualitative data within systemic, ecological and developmental perspectives. Having considered the methodological difficulties and the ideological controversies of the concept it is suggested a cautious investigation of meaning before the application of the term.
\end{abstract}

Key words: Positive psychology; resilience; family resilience.

\section{A PSICOLOGIA POSITIVA - ÊNFASE NOS ASPECTOS "VIRTUOSOS"}

Durante todo o ano de 1998, Martin Seligman, na condição de presidente da American Psychological Association, escreveu artigos mensais que focalizavam a necessidade de mudança no foco das contribuições da Psicologia, ainda centrado numa prática historicamente orientada para a compreensão e tratamento de patologias. Segundo esse importante pesquisador, a ciência psicológica tem "esquecido" ou negligenciado a sua mais importante missão: a de construir uma visão de ser humano com ênfase em aspectos "virtuosos". Nesta ótica, o movimento intitulado
Psicologia Positiva vem afirmar-se na edição especial de 2001 do periódico American Psychologist, e é definido como uma "tentativa de levar os psicólogos contemporâneos a adotarem uma visão mais aberta e apreciativa dos potenciais, das motivações e das capacidades humanas" (Sheldon \& King, 2001, p. 216). Tendo em vista esta perspectiva, a ciência psicológica busca transformar velhas questões em novas possibilidades de compreensão de fenômenos psicológicos como felicidade, otimismo, altruísmo, esperança, alegria, satisfação e outros temas humanos, tão importantes para a pesquisa quanto depressão, ansiedade, angústia e agressividade. Trata-se, portanto, de uma psicologia que almeja

Doutora em Educação: Psicologia da Educação pela Pontifícia Universidade Católica de São Paulo. Centro de Estudos Psicológicos sobre Meninos e Meninas de Rua, Departamento de Educação e Ciências do Comportamento Fundação Universidade Federal do Rio Grande.

Endereço para correspondência: Rua General Portinho, n. 35, apto 802, CEP 96200-210, Rio Grande-RS. E-mail: yunes@ vetorialnet.com.br 
antes de tudo romper com o viés "negativo" e reducionista de algumas tradições epistemológicas que têm adotado o ceticismo diante de expressões salutogênicas de indivíduos, grupos ou comunidades. Entretanto, postular uma ciência que focalize potencialidades e qualidades humanas exige tanto esforço, reflexão e seriedade conceitual, teórica e metodológica quanto o estudo de distúrbios e desordens humanas. $\mathrm{Na}$ esteira destas iniciativas, alguns fenômenos indicativos de "vida saudável" têm sido referidos como sistemas de adaptação ao longo do desenvolvimento (Masten, 2001), dentre os quais destaco a resiliência.

\section{O CONCEITO DE RESILIÊNCIA}

Resiliência é freqüentemente referida por processos que explicam a "superação" de crises e adversidades em indivíduos, grupos e organizações (Yunes \& Szymanski, 2001, Yunes, 2001, Tavares, 2001). Por tratar-se de um conceito relativamente novo no campo da Psicologia, a resiliência vem sendo bastante discutida do ponto de vista teórico e metodológico pela comunidade científica. Alguns estudiosos reconhecem a resiliência como um fenômeno comum e presente no desenvolvimento de qualquer ser humano (Masten, 2001), e outros enfatizam a necessidade de cautela no uso "naturalizado" do termo (Martineau, 1999; Yunes, 2001).

Na língua portuguesa, a palavra resiliência, aplicada às ciências sociais e humanas, vem sendo utilizada há poucos anos. Neste sentido, seu uso no Brasil ainda se restringe a um grupo bastante limitado de pessoas de alguns círculos acadêmicos. Muitos profissionais da área da Psicologia, da Sociologia ou da Educação nunca tiveram contato com a palavra e desconhecem seu uso formal ou informal, bem como sua aplicação em qualquer das áreas da ciência. Por outro lado, profissionais das áreas da Engenharia, Ecologia e Física, e até mesmo da Odontologia, revelam certa familiaridade com a palavra, quando ela se refere à resistência de materiais. Nos diferentes países da Europa, nos Estados Unidos e no Canadá, a palavra resiliência vem sendo utilizada com frequiência, não só por profissionais das ciências sociais e humanas, mas também em referências da mídia a pessoas, lugares, ações e coisas em geral. Uma pesquisadora canadense (Martineau, 1999) cita, em seu importante trabalho de doutorado sobre resiliência, alguns exemplos das contradições deste uso coloquial, quando pessoas famosas são consideradas "resilientes" pela mídia tanto por tolerarem como por terminarem seus casamentos. Pessoas ou coisas (desde pneus de carros até cremes para a pele) que tanto resistem como provocam mudanças também são descritas como "resilientes" nos comerciais de jornais ou TV. Em diálogos informais, as pessoas classificam-se como "resilientes" ou "não resilientes", o que sugere uma "objetificação" ou "coisificação" do conceito.

Não obstante, no Brasil, a palavra resiliência e seus significados ainda permanecem como "ilustres desconhecidos" para a grande maioria das pessoas, enquanto nos países mencionados acima o termo é inclusive muito utilizado para referendar e direcionar programas políticos de ação social e educacional, o que aqui (talvez felizmente...) ainda parece estar longe de acontecer.

Para melhor exemplificar a diferença cultural nas prioridades de significado da palavra resiliência nas línguas portuguesa e inglesa, recorreu-se a dicionários atualizados. O dicionário de língua portuguesa de autoria de Ferreira (1999), conhecido como Novo Aurélio, diz que, na Física, resiliência "é a propriedade pela qual a energia armazenada em um corpo deformado é devolvida quando cessa a tensão causadora duma deformação elástica". No sentido figurado, o mesmo dicionário aponta o termo como "resistência ao choque". O dicionário de língua inglesa Longman Dictionary of Contemporary English (1995) oferece duas definições de resiliência, sendo a primeira: "habilidade de voltar rapidamente para o seu usual estado de saúde ou de espírito depois de passar por doenças, dificuldades etc.: resiliência de caráter"1. A segunda explicação para o termo encontrada no mesmo dicionário afirma que resiliência "é a habilidade de uma substância retornar à sua forma original quando a pressão é removida: flexibilidade"2.

Como se pode ver, os dois dicionários apontam para conceituações semelhantes e ao mesmo tempo divergentes, pois no dicionário de português a referência é feita apenas à resiliência de materiais, e mesmo no sentido figurado, nada é especificamente claro para a compreensão do que seja a resiliência quando se trata de pessoas. Já o dicionário de inglês confirma a prioridade ou maior familiaridade para o uso do termo em fenômenos humanos, apontando em primeiro plano a definição neste sentido.

1 Original em inglês: "the ability to return quickly to your usual health or state of mind after suffering an illness, difficulties etc.: resilience of character".

2 Original em inglês: "the ability of a substance to return to its former shape when pressure is removed: flexilibity". 


\section{Origens do conceito}

A noção de resiliência vem sendo utilizada há muito tempo pela Física e Engenharia, sendo um de seus precursores o cientista inglês Thomas Young, que, em 1807, considerando tensão e compressão, introduz pela primeira vez a noção de módulo de elasticidade. Young descrevia experimentos sobre tensão e compressão de barras, buscando a relação entre a força que era aplicada num corpo e a deformação que esta força produzia. Esse cientista foi também o pioneiro na análise dos estresses trazidos pelo impacto, tendo elaborado um método para o cálculo dessas forças (Timosheibo, 1983). Silva Jr. (1972) denomina como resiliência de um material, correspondente a determinada solicitação, a energia de deformação máxima que ele é capaz de armazenar sem sofrer deformações permanentes. Dita de uma outra maneira, a resiliência refere-se à capacidade de um material absorver energia sem sofrer deformação plástica ou permanente. Nos materiais, portanto, o módulo de resiliência pode ser obtido em laboratório através de medições sucessivas ou da utilização de uma fórmula matemática que relaciona tensão e deformação e fornece com precisão a resiliência dos materiais. É importante ressaltar que diferentes materiais apresentam diferentes módulos de resiliência.

\section{A resiliência como um construto psicológico}

Em Psicologia, o estudo do fenômeno da resiliência é relativamente recente. Vem sendo pesquisado há cerca de trinta anos, mas apenas nos últimos cinco anos os encontros internacionais têm trazido este construto para discussão. Sua definição não é clara, tampouco precisa quanto na Física ou na Engenharia, e nem poderia sê-lo, haja vista a complexidade e multiplicidade de fatores e variáveis que devem ser levados em conta no estudo dos fenômenos humanos.

Os precursores do termo resiliência na Psicologia são os termos invencibilidade ou invulnerabilidade, ainda bastante referidos na literatura. Vários autores (Masten \& Garmezy, 1985; Rutter, 1985; Werner \& Smith, 1992) relatam que "em 1974, o psiquiatra infantil E. J. Anthony introduziu o termo invulnerabilidade na literatura da psicopatologia do desenvolvimento para descrever crianças que, apesar de prolongados períodos de adversidades e estresse psicológico, apresentavam saúde emocional e alta competência" (Werner \& Smith, 1992, p. 4). Alguns anos depois, já se discutia a aplicação do termo, que parecia sugerir que as crianças seriam totalmente imunes a qualquer tipo de desordem, independentemente das circunstâncias. Como afirmaram Masten e Garmezy (1985): "um termo menos olímpico como resiliência ou resistência ao estresse, se fazia necessário" (p. 12). Segundo Rutter (1985, 1993), um dos pioneiros no estudo da resiliência no campo da Psicologia, invulnerabilidade passa uma idéia de resistência absoluta ao estresse, de uma característica imutável, como se fôssemos intocáveis e sem limites para suportar o sofrimento. Rutter (1993) considera que invulnerabilidade passa somente a idéia de uma característica intrínseca do indivíduo, e as pesquisas mais recentes têm indicado que a resiliência ou resistência ao estresse é relativa, que suas bases são tanto constitucionais como ambientais, e que o grau de resistência não tem uma quantidade fixa, e sim, varia de acordo com as circunstâncias (Rutter, 1985). Resiliência e invulnerabilidade não são termos equivalentes, afirmam Zimmerman e Arunkumar (1994). Segundo estes autores, resiliência refere-se a uma "habilidade de superar adversidades, o que não significa que o indivíduo saia da crise ileso, como implica o termo invulnerabilidade" (p. 4). Apesar destas considerações, é esta versão inicial de resiliência como invulnerabilidade ou resistência às adversidades que ainda vem orientando a produção científica de muitos pesquisadores da área. Tal perspectiva tem dado lugar à construção de um conceito que define a resiliência como um conjunto de traços e condições que podem ser replicados, conforme afirma Martineau (1999) em sua análise crítica sobre o discurso dos denominados por ela experts no assunto. A autora detectou três perspectivas distintas nos discursos vigentes sobre resiliência. Em primeiro lugar, cita o discurso dominante e bem-documentado dos especialistas, resultante de elaborados estudos psicométricos e da análise estatística dos dados obtidos por medidas e em ambientes controlados através de escores de testes, notas de escola e perfis de personalidade ou temperamento. Estes são alguns exemplos de instrumentos utilizados para se chegar a um conjunto de características e traços que identificam a "criança/pessoa resiliente". Martineau sumariza que os principais traços vistos como características fixas da resiliência, que formam um consenso na opinião de diversos autores são: sociabilidade, criatividade na resolução de problemas e um senso de autonomia e de proposta. Estas medidas do observável e de alguma maneira mensurável acabam por definir o que os autores (experts) chamam de resiliência. Em segundo lugar, a autora analisa o discurso experiencial, menos valorizado e 
subordinado ao discurso dos especialistas, cuja base são os estudos qualitativos, com dados obtidos a partir de histórias de vida de adultos relatadas a psicoterapeutas (e identificados por outras pessoas como "resilientes"), nas quais "estão embutidas as idiossincrasias de memória, narrativa, identidade, interpretação e subjetividade" (Martineau, 1999, p. 73). São histórias de vida construídas e reconstruídas através das múltiplas interpretações do indivíduo. Em terceiro lugar, Martineau apresenta o discurso de pessoas que trabalham diretamente com crianças e adolescentes (educadores, psicólogos, assistentes sociais), uma perspectiva de resiliência ainda em construção, que sintetiza aspectos dos dois discursos, dos experts e do experiencial. Ao posicionar-se, Martineau afirma que reificar/replicar as características de uma determinada criança como "resiliente" (através da mensuração de um conjunto de traços) é negar que resiliência é contingente/provisória, imprevisível e dinâmica.

\section{As pesquisas sobre resiliência}

\section{O foco no indivíduo}

Vários autores estrangeiros, principalmente dos Estados Unidos e do Reino Unido, têm desenvolvido pesquisas sobre resiliência. A maioria dos estudos tem por objetivo estudar a criança ou o adolescente numa perspectiva individualista, que foca traços e disposições pessoais. Ilustrativa desta tendência é a definição adotada pelo Projeto Internacional de Resiliência, coordenado por Edith Grotberg e apoiado pela Bernard van Leer Foundation: "Resiliência é uma capacidade universal que permite que uma pessoa, grupo ou comunidade previna, minimize ou supere os efeitos nocivos das adversidades". (Grotberg, 1995, p. 7). Muitos pesquisadores do desenvolvimento humano estudam os padrões de adaptação individual da criança associados ao ajustamento apresentado na idade adulta, ou seja, "procuram compreender como adaptações prévias deixam a criança protegida ou sem defesa quando exposta a eventos estressores" (Hawley e DeHann, 1996), e estudam também como os "padrões particulares de adaptação, em diferentes fases de desenvolvimento, interagem com mudanças ambientais externas" (Sroufer \& Rutter, 1984, p. 27). Entre as publicações mais citadas estão as primeiras no assunto, intituladas Vulnerable but Invincible (Vulneráveis, porém invencíveis), Overcoming the Odds (Superando as adversidades), ambos de Werner e Smith $(1982,1992)$ e The Invulnerable Child (A criança invulnerável) de Anthony e Cohler (1987). A importância destes estudos está na característica long-term, ou seja, são estudos longitudinais que acompanham o desenvolvimento do indivíduo desde a infância até a adolescência ou idade adulta. Segundo Werner e Smith (1992), poucos investigadores têm acompanhado populações de "alto risco" desde a infância e adolescência até a idade adulta com o objetivo de monitorar efeitos dos fatores de risco e os fatores de proteção que operam durante os anos de desenvolvimento do indivíduo. $\mathrm{O}$ estudo longitudinal realizado por Werner (1986, 1993), Werner e Smith $(1982,1989$, 1992) e outros colaboradores durou cerca de 40 anos, tendo se iniciado em 1955. De acordo com Martineau (1999), esse estudo não tinha como proposta inicial estudar a questão da resiliência, mas investigar os efeitos cumulativos da pobreza, do estresse perinatal e dos "cuidados familiares deficientes"3 no desenvolvimento físico, social e emocional das crianças. A pesquisa acompanhou 698 crianças nascidas em Kauai, uma ilha do Havaí. As crianças foram avaliadas com um ano de idade (incluindo entrevistas com os pais) e acompanhadas até as idades de $2,10,18$ e 32 anos. O foco da pesquisa relatada no livro Vulnerable but invincible foram 72 crianças (42 meninas e 30 meninos) com uma história de quatro ou mais fatores de risco, a saber: pobreza, baixa escolaridade dos pais, estresse perinatal ou baixo peso no nascimento, ou ainda a presença de deficiências físicas. Uma proporção significativa dessas crianças era proveniente de famílias cujos pais eram alcoólatras ou apresentavam distúrbios mentais. Para surpresa dos pesquisadores, nenhuma destas crianças desenvolveu problemas de aprendizagem ou de comportamento (Werner \& Smith, 1982), o que foi considerado então como "sinal de adaptação ou ajustamento". Diante desses indicativos, as crianças foram denominadas "resilientes" pelas pesquisadoras, pois nesse período já se discutia muito sobre o que haveria de diferente nas crianças que eram criadas em circunstâncias adversas e não eram atingidas (embora não fique bem claro o que significa ser ou não atingido). Uma outra amostra estudada por Werner (1986) foi um subgrupo de 49 jovens da mesma ilha, cujos pais tiveram sérios problemas devido ao abuso do álcool e sofreram conflitos familiares desde cedo, além de viver em condições de pobreza. Por volta dos 18 anos, $41 \%$ desse grupo apresentaram problemas de aprendizagem, ao contrário dos restantes 59\%. Esse último grupo foi denominado grupo "resiliente", e diferia do primeiro por um número de medidas obtidas através de entrevistas com pais e entrevistas retrospectivas com os próprios jovens. Os fatores que discriminaram o grupo "resiliente", tanto nas pesquisas de 1982 como na de 1986, incluíam: temperamento das crianças/jovens (percebidos como

Poor parenting no original em inglês (Martineau, 1999, p. 102) 
afetivos e receptivos); melhor desenvolvimento intelectual; maior nível de auto-estima; maior grau de autocontrole; famílias menos numerosas; menor incidência de conflitos nas famílias. Como se pode notar, as autoras atribuíram as diferenças às características constitucionais das crianças e ao ambiente criado pelos cuidadores da infância. Na última etapa dessa ambiciosa pesquisa, Werner e Smith (1992, p. 192) concluíram que "um terço dos indivíduos considerados de alto risco tornaram-se adultos competentes capazes de amar, trabalhar, brincar/divertir-se e ter expectativas". Conforme afirma Martineau (1999), a "resiliência" a que as autoras se referem foi identificada nas pesquisas iniciais como "invulnerabilidade às adversidades", conceituação reformulada e mais tarde definida como "habilidade de superar as adversidades". Werner (1993) notou que o componente-chave do efetivo coping ${ }^{4}$ dessas pessoas é o sentimento de confiança que o indivíduo apresenta de que os obstáculos podem ser superados, o que confirma a ênfase colocada nos componentes psicológicos individuais, de um "algo interno", apesar das inúmeras referências feitas pelas autoras aos aspectos protetores decorrentes de relações parentais satisfatórias e da disponibilidade de fontes de apoio social na vizinhança, escola e comunidade.

Outro importante e já citado pensador do assunto é o psiquiatra britânico Michael Rutter, que, pelo número de publicações e pesquisas empíricas, tem orientado até hoje o curso dos projetos na área. Seus trabalhos mais conhecidos datam do início dos anos 1970, com a investigação de diferenças entre meninos e meninas provenientes de lares desfeitos por conflitos (Rutter, 1970) e das relações entre os efeitos destes conflitos parentais no desenvolvimento das crianças (Rutter, 1971). Seus resultados indicaram que os meninos são mais vulneráveis que as meninas, não somente a estressores físicos, mas também aos psicossociais. Um de seus marcantes trabalhos nesta área foi desenvolvido com uma amostra de sujeitos da Ilha de Wight e da cidade de Londres (Rutter, 1979, 1981b), os quais haviam experienciado discórdias na família dos pais, eram de camadas sociais de baixa renda, de famílias numerosas, com história de criminalidade de um dos pais, doença mental da mãe ou institucionalizados sob custódia do governo. Seus resultados deram origem à sua afirmação bastante divulgada de que um único estressor não tem impacto significativo, mas que a combinação de dois ou mais estressores pode diminuir a possibilidade de

\footnotetext{
4 A palavra coping é geralmente utilizada no original em inglês para referir-se a esforços cognitivos e comportamentais para lidar com demandas específicas de situações adversas e avaliadas como sobrecarregando ou excedendo os recursos pessoais.
}

conseqüências positivas (positive outcomes) no desenvolvimento, e que estressores adicionais aumentam o impacto de outros estressores presentes. Em 1981, Rutter publica um livro que trata da relação entre a ausência da figura materna e o desenvolvimento de psicopatologias na criança (Rutter, 1981a), com um capítulo que versa sobre resiliência e o comportamento parental de adultos que na infância tenham sofrido abandono. Entre as principais questões levantadas pelo autor aparece a mais freqüente formulação inicial dos estudos sobre resiliência: por que, apesar de passar por terríveis experiências, alguns indivíduos não são atingidos e apresentam um desenvolvimento estável e saudável? Rutter (1987) define resiliência como uma "variação individual em resposta ao risco", e afirma "que os mesmos estressores podem ser experienciados de maneira diferente por diferentes pessoas". De acordo com esse autor, a resiliência "não pode ser vista como um atributo fixo do indivíduo", e "se as circunstâncias mudam, a resiliência se altera" (p. 317). Mais recentemente, Rutter (1999) define a resiliência de uma forma mais ampla: "o termo refere-se ao fenômeno de superação de estresse e adversidades" (p. 119), e categoricamente afirma que "resiliência não constitui uma característica ou traço individual" (p. 135). Entre outros pontos, nessa mesma publicação, Rutter (1999) chama a atenção para a extensão e variedade das respostas psicológicas implicadas na questão, que envolvem processos a serem cuidadosamente examinados. Mas o foco de suas considerações mantém-se no indivíduo, em especial na criança. Muito recentemente, importantes pesquisadores do assunto (Luthar, Cicchetti \& Becker, 2000) manifestaram-se a esse respeito, defendendo uma posição mediadora no sentido de enfatizar o caráter processual da questão da resiliência. Segundo os autores mencionados, há uma "confusão" entre Processo e Traço nos estudos, em decorrência do ocasional uso do termo "criança resiliente" por pesquisadores que, na verdade, são adeptos de uma visão dinâmica da resiliência, ou seja, processual. Luthar e cols. (2000) reiteram que o termo "criança resiliente", empregado por muitos autores, não se refere a atributos pessoais, mas sim à pressuposição de condições de resiliência, a saber: a) a presença de fatores de risco ao bem-estar da criança, e b) a adaptação positiva da criança, apesar das adversidades.

A maioria destas considerações, em especial as mais atuais (Luthar e cols., 2000; Rutter, 1993, 1999), procuram dar ao conceito um toque de relatividade, nem sempre presente nos estudos quantitativos que usam medidas e critérios estatísticos (talvez seja o que Luthar e cols., 2000 chamam de "rigor científico", p. 556) baseados em comportamentos observáveis para identificar crianças "resilientes" num determinado ponto da vida. 
O estudo desenvolvido por Martineau (1999) deixa claro que "resiliência tem diferentes formas entre diferentes indivíduos em diferentes contextos, assim como acontece com o conceito de risco" (p. 103).

A perspectiva no indivíduo é notória também na introdução de diversos estudos que investigam resiliência. As questões relativas a "habilidades individuais" são em geral ilustradas com pequenas histórias de pessoas dentre as quais algumas conseguem superar os momentos de crise e outras sucumbem, apesar de todas terem trajetórias semelhantes. Desta forma, o foco no indivíduo busca identificar resiliência a partir de características pessoais, como sexo, temperamento e background genético, apesar de todos os autores acentuarem em algum momento o aspecto relevante da interação entre bases constitucionais e ambientais da questão da resiliência.

Muitos destes trabalhos situam-se na área da psicopatologia do desenvolvimento, a qual tem sido descrita como a ciência que estuda as "origens e o curso dos padrões individuais de comportamentos de desadaptação" (Sroufer \& Rutter, 1984, p. 18), cuja ênfase está no desenvolvimento dos comportamentos patológicos ao longo do tempo (Hawley \& DeHann, 1996). Em muitos casos, o patológico estudado nos trabalhos sobre resiliência refere-se tão-somente a populações em desvantagem social ou a minorias étnicas. Martineau (1999), ao comentar o estudo pioneiro de Werner e Smith $(1982,1992)$ realizado na ilha de Kauai, refere que uma consideração que merece ser feita diz respeito à construção inicial do que as autoras chamaram de "pobreza", numa sociedade rural, não industrializada, cuja população era predominantemente constituída por havaianos ou asiáticos. A eles foi atribuída pobreza porque, por volta de 1950, a economia do local girava em torno da pesca e da cana-de-açúcar. Segundo Martineau, as pesquisadoras do cohort $^{5}$ em Kauai fizeram uma descrição dos pais das crianças (classificados como "não habilidosos e grosseiros") com indicações de que eles estavam sendo comparados com populações urbanas de áreas industrializadas que tinham acesso a serviços médicos e educacionais e a outras facilidades. Ilustrativo desta visão que permeia diversas pesquisas sobre resiliência é um dos artigos de Garmezy (1991) sobre "Resiliência e vulnerabilidade associados à pobreza" em que o autor relata que, desde o início da década de 1970, seu grupo tem feito esforços no sentido de compilar os atributos de crianças negras que vivem em circunstâncias desfavoráveis, ou de baixa renda, mas que denotam

5 Grupo de pessoas que nasceram e viveram durante o mesmo período histórico (Garbarino \& Abramovitz, 1992). competência. Esta atenção dos pesquisadores da resiliência dirigida especialmente a estas populações de imigrantes, pobres ou que vivem em circunstâncias de "desvantagem", parece refletir uma preocupação daquelas sociedades com a "ameaça" que estes grupos podiam (ou podem) representar para as camadas das classes dominantes. Penso que é com esta conotação que as populações têm sido denominadas "populações em situação de risco", ou de "alto risco". Risco para quem? Dependendo da maneira como tratarmos os estudos sobre resiliência em nosso país, poderemos cair neste mesmo viés. Por isso, esta é uma questão que merece ser analisada com muita cautela. Foi a partir das pesquisas de Michael Rutter, Emily Werner, Ruth Smith e de outros importantes nomes, como Norman Garmezy, Ann S. Masten, Suniya Luthar, que se delineou a questão da resiliência e emergiram com essa construção várias constelações temáticas e conceituais que passaram a fazer parte dos relatos empíricos e até os dias de hoje exercem uma forte influência no discurso científico, como risco, vulnerabilidade, estresse, coping, competência e proteção (uma revisão destes conceitos pode ser encontrada em Yunes \& Szymanski, 2001).

\section{O foco na família}

Resiliência em famílias é um construto relativamente novo (Hawley \& DeHann, 1996). Dos estudos sobre a resiliência no indivíduo, poucos têm considerado explicitamente as contribuições da família (Rutter, 1985; Werner \& Smith, 1982). No geral, os estudos sobre família enfatizam os aspectos deficitários e negativos da convivência familiar. Uma criança "sintomática" ou um adolescente "com problemas na escola" logo dirigem o pensamento das pessoas para os possíveis desajustes de suas famílias. $\mathrm{O}$ interesse pela resiliência em famílias vem contribuir para redirecionar esse ciclo de raciocínio, trazendo para o mundo familiar uma ênfase "salutogênica" (Antonovsky \& Sourani, 1988), ou seja, significa focar e pesquisar os aspectos sadios e de sucesso do grupo familiar ao invés de destacar seus desajustes e falhas.

A realização de minha pesquisa bibliográfica sobre o tema indica ter sido no final dos anos 1980 que as questões sobre coping, competência, desafios e adaptação do grupo familiar começaram a ser divulgadas. Um dos primeiros trabalhos específicos desta área foi publicado por McCubbin e McCubbin (1988) sobre a "tipologia de famílias resilientes", partindo da definição segundo a qual famílias "resilientes" são aquelas que resistem aos problemas decorrentes de mudanças e "adaptam-se" às situações de crise. Os autores estavam interessados em investigar características, dimensões e propriedades de famílias que as ajudariam a lidar 
com situações de crise, como tragédias ou simples transições no ciclo de vida e os efeitos na dinâmica familiar, como o nascimento do primeiro filho, sua adolescência ou a saída do filho de casa para a universidade. Para tal estudo, os autores usaram o modelo das teorias de estresse para guiar as investigações e explicar o comportamento das famílias em situações que eles chamaram de "normativas" (as transições esperadas decorrentes do próprio desenvolvimento) e "não normativas" (catástrofes e outras crises não esperadas no desenvolvimento). Os autores chegaram a quatro tipos de famílias: vulneráveis, seguras, duráveis e regenerativas, dependendo da forma como a unidade familiar lidava com as situações e em função do relacionamento entre os membros. Esse trabalho é importante por ter lançado um desafio aos pesquisadores do tema, chamando a atenção para a necessidade não só de estudar a resiliência em famílias, mas também de entendê-la em diferentes classes sociais e étnicas. Além disso, os autores delinearam a importância de se olhar para o grupo familiar, sem esquecer a sua inserção e relação com a comunidade, e a importância de se incrementarem políticas de programas de apoio às famílias. Por outro lado, os autores acabaram contribuindo com outros "rótulos" (como por exemplo, os tipos mencionados acima) ou categorias extras e derivativas do conceito de resiliência.

O potencial de pesquisas nesta área passou a ser explorado e alguns autores (Walsh, 1996; Hawley \& DeHann, 1996) passaram a preocupar-se em esclarecer, conceituar, definir e propor novas perspectivas teóricas de resiliência em famílias.

Froma Walsh apresenta uma longa trajetória no estudo de famílias na cidade de Chicago e várias publicações sobre o tema (Walsh, 1993, 1996, 1998, 1999). Seus achados resultam dos anos de docência, da experiência no atendimento clínico e orientação de famílias e da prática de supervisão de casos acompanhados por outros profissionais de diferentes áreas. Segundo Walsh (1996), "o foco da resiliência em família deve procurar identificar e implementar os processos-chave que possibilitam que famílias não só lidem mais eficientemente com situações de crise ou estresse permanente, mas saiam delas fortalecidas, não importando se a fonte de estresse é interna ou externa à família. Desta forma, a unidade funcional da família estará fortalecida e possibilitada a resiliência em todos os membros" (p. 263) . Essa mesma autora, numa publicação mais recente, sintetiza afirmando que "o termo resiliência em família refere-se a processos de adaptação e coping na família enquanto uma unidade funcional". (Walsh, 1998, p. 14). Na tentativa de integrar as contribuições das pesquisas e da literatura sobre a resiliência no indivíduo e na família, Hawley e DeHann (1996) propõem a seguinte definição: "Resiliência em família descreve a trajetória da família no sentido de sua adaptação e prosperidade diante de situações de estresse, tanto no presente como ao longo do tempo. Famílias resilientes respondem positivamente a estas condições de uma maneira singular, dependendo do contexto, do nível de desenvolvimento, da interação resultante da combinação entre fatores de risco, de proteção e de esquemas compartilhados" (p. 293).

Pode-se notar que, nas concepções destes dois últimos autores citados, resiliência em família aparece definida de forma similar à encontrada na literatura em que o foco é o indivíduo. Isso não poderia ser diferente, já que se trata de concepções acerca do mesmo fenômeno. Entretanto, o nível de análise é que deve ser diferente, pois, quando se trata de resiliência em família, o fenômeno deixa de ser considerado como uma característica individual que sofre a influência da família, e passa a ser conceituado como uma qualidade sistêmica de famílias (Hawley \& DeHann, 1996).

Como já apontado anteriormente neste trabalho, vários autores indicaram nos seus estudos sobre resiliência no indivíduo a influência de relações com pessoas significativas e próximas como apoio para superação das adversidades da vida (Rutter, 1987; Werner e Smith, 1992; Werner, 1993). De acordo com Walsh (1998), a maioria das pesquisas e teorias sobre resiliência tem abordado o contexto relacional de maneira limitada, em termos da influência de uma única pessoa significativa numa relação diádica. A autora afirma: "A compreensão global de resiliência requer um complexo modelo interacional. A teoria sistêmica expande nossa visão de adaptação individual para a mutualidade de influências através dos processos transacionais" (p. 12). Walsh propõe que sejam estudados processos-chave da resiliência em famílias, os quais fundamentam a sua proposta de abordagem denominada "funcionamento familiar efetivo". A autora organizou seus conhecimentos nesta área e propõe um panorama conceitual dentro de três domínios: sistema de crenças da família, padrões de organização e processos de comunicação. $O$ quadro abaixo apresenta um sumário dos processos-chave da resiliência em família segundo Walsh (1998): 
Quadro 1. Resumo dos processos-chave da resiliência em famílias, traduzido pela autora deste trabalho, extraído do livro Strengthening family resilience (Walsh, 1998).

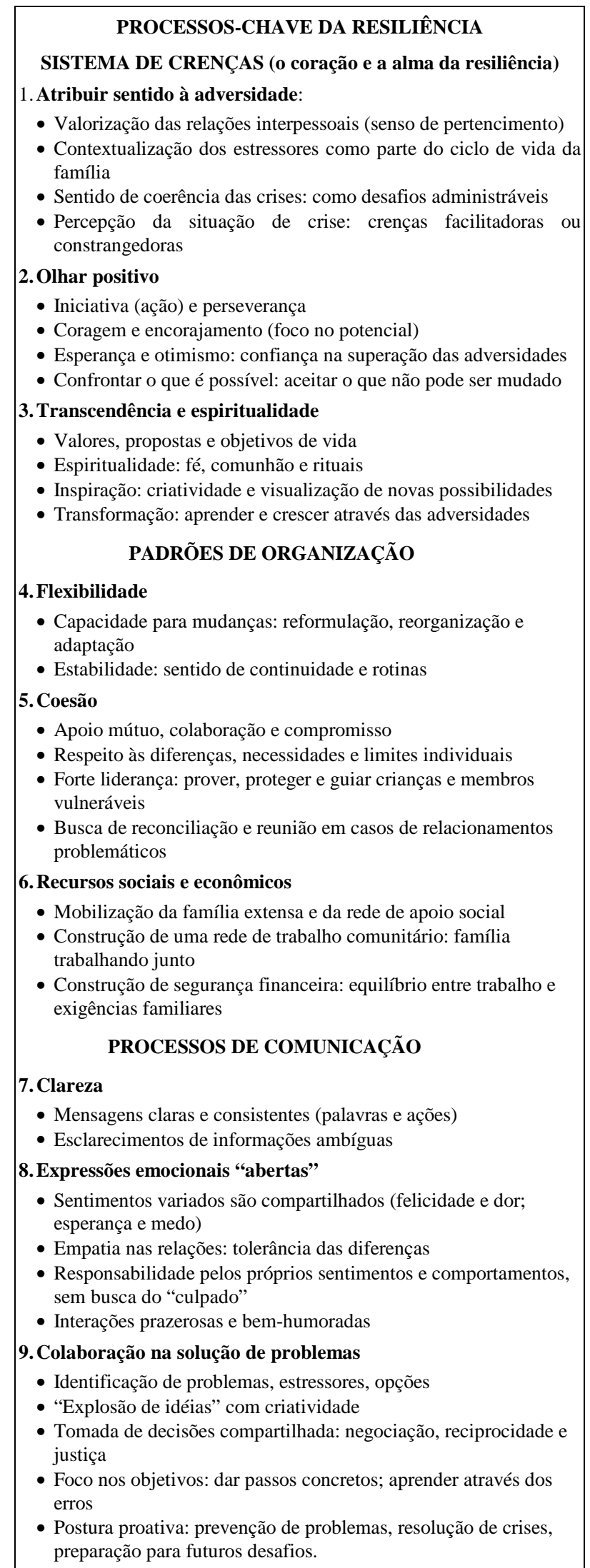

Estes processos podem estar organizados e expressar-se de diferentes formas e níveis, haja vista que servem a diferentes constelações, valores, recursos e desafios das famílias (Walsh, 1998).

Apesar de os pesquisadores da resiliência em família defenderem teorias que ampliam a compreensão anteriormente limitada pelo espectro no indivíduo, surgem outras questões semelhantes às anteriores. Serão os critérios apresentados por Walsh (1998) suficientes para definir resiliência em família? Como evitar que o conceito de resiliência seja usado no Brasil por políticas públicas que apóiam e mantêm as desigualdades sociais, baseadas no "sucesso" ou "insucesso" de indivíduos e das famílias? Será possível escapar da concepção de resiliência dominante no discurso dos especialistas e apontada por Martineau (1999, p. 11): "a resiliência como um código ideológico de conformidade ao sucesso prescrito por normas sociais vigentes". Um exemplo desta tendência é a frequiência da afirmação do papel crítico da pobreza nos estudos sobre resiliência e desenvolvimento humano. Embora a situação de pobreza não seja apontada como a causa direta de deficiências, sugere-se que as circunstâncias associadas a ela apresentam alta correlação com respostas adversas (Garmezy, 1991; Thompson, 1991). Até mesmo os principais mentores do conceito da resiliência, que em alguns momentos apresentam afirmações contrárias a estas concepções, acabam de alguma forma caindo no viés daqueles que patologizam a pobreza e às vezes indiretamente acabam por "culpar a vítima" (Rutter, 1996). Uma pesquisa realizada recentemente por mim sobre a questão da resiliência em famílias de baixa renda (Yunes, 2001) evidenciou dois pontos importantes: a) ao fazer referências a famílias de baixa renda, trabalhadores sociais de diferentes áreas denotam uma tendência a lhes atribuir a condição de "nãoresiliência" a priori. Isso sugere a inspiração ideológica do conceito de resiliência quando aplicado a pessoas ou famílias em situação de pobreza; b) os potenciais critérios ou indicadores de resiliência em família mostraram-se problemáticos para representar os modos de enfrentamento de dificuldades das famílias na condição de pobreza. Na realidade, as famílias estudadas mostraram que "enfrentaram e enfrentam as adversidades da pobreza" à sua maneira e no seu estilo de "ser família". Portanto, o dinamismo e a complexidade de fatores relacionais, sociais e históricos que permeiam os processos familiares bloqueiam o enfeixamento de toda esta diversidade dentro de um mesmo quadro de universalidade conceitual para ser categorizado sob o nome de 
"resiliência em famílias pobres". De qualquer forma, guardadas as considerações que desenvolvi até o momento, é impossível negar que a resiliência em famílias é um campo fértil para futuras pesquisas, explorado por poucos, até o momento.

\section{REFLEXÕES FINAIS}

$\mathrm{Na}$ primeira parte deste artigo apresentei a questão da resiliência inserida no movimento da Psicologia Positiva, reafirmando a sua importância para a determinação de novos horizontes para pesquisas nas áreas das ciências humanas e sociais. Num segundo momento, busquei revisar a noção de resiliência sob diferentes perspectivas, demonstrando que, no enfoque da Psicologia, se tem procurado compreender os processos e condições que possibilitam a "superação" de situações de crises e adversidades. Foram apresentadas as idéias de Martineau (1999), com destaque para os discursos sobre resiliência identificados pela autora, como: o discurso dos experts que fala sobre traços e características individuais; o discurso experiencial, baseado em dados qualitativos das histórias de vida, relatos e narrativas construídas e reconstruídas pelas interpretações de cada indivíduo; e o discurso dos educadores, psicólogos e assistentes sociais, que denota a resiliência na perspectiva da "síntese" entre os dois discursos mencionados, o dos experts e o experencial. Na categoria dos experts, temos ainda um dos estudos mais recentes de Rutter (1999), que, apesar de manter suas considerações no indivíduo, pondera afirmações de que resiliência não é uma característica ou traço individual, mas que processos psicológicos devem ser cuidadosamente examinados, o que, de certa forma, coincide com a posição de Martineau (1999) sobre o assunto. Conforme demonstrado, outros importantes pesquisadores contemporâneos, como Luthar, Cicchetti e Becker (2000) e Masten (2001), também defendem claramente o caráter processual da questão da resiliência.

Quanto aos pesquisadores da resiliência em famílias, pode-se verificar que os debates neste campo ainda estão em fases iniciais de investigação. As discussões têm contribuído para reverter o panorama "negativo" no qual o mundo familiar tem como figura principal os desajustes e conflitos. Focar, pesquisar, compreender e fortalecer os aspectos sadios e de sucesso do grupo familiar significa estudar processos e percepções de elementos das experiências de vida, compreendidos na ótica sistêmica, ecológica
(Bronfenbrenner, 1996,1998) e de desenvolvimento, conforme mostra a abordagem de Walsh $(1996,1998)$. Poder-se-ia dizer que este corpo de conhecimentos forma um "discurso subordinado", não por "curvar-se" ou submeter-se às regras do discurso dominante (muito ao contrário), mas por estar ainda em construção (Yunes, 2001). Assim, destaco a importância de pensar a questão da resiliência, seja em crianças, adolescentes, adultos, idosos ou grupos familiares, tendo-se em mente as controvérsias apontadas neste trabalho, cujo objetivo foi insinuar um "discurso crítico". Este discurso sugere uma cautelosa investigação de sentido que possibilite o uso criterioso do termo. O conceito é interessante para ser pesquisado, principalmente por trazer o desafio para a construção de linhas de pesquisa centradas num conhecimento que justifique os aspectos de saúde da condição humana sem que se incorra em classificações ou rotulações ideologicamente determinadas.

\section{REFERÊNCIAS}

Anthony, E. J. \& Cohler, B. J. (1987) The invulnerable child. New York: Guilford.

Antonovsky, A. \& Sourani, T. (1988) Family sense of coherence and family sense of adaptation. Journal of Marriage and the Family, 50, 79-92.

Bronfenbrenner, U. (1996). A ecologia do desenvolvimento humano: experimentos naturais e planejados (M. A. V. Veronese, Trad) Porto Alegre: Artes Médicas. (Original publicado em 1979)

Bronfenbrenner, U. \& Morris, P. (1998). The ecology of developmental processes. Em W. Damon (Org.), Handbook of child psychology V.1 (pp. 993-1027). New York, NY: John Wiley \& Sons.

Ferreira, A. B. de H. (1999) Novo Aurélio: o dicionário do Século XXI. São Paulo: Nova Fronteira.

Garbarino, J. \& Abramowitz, R. H. (1992) Sociocultural risk and opportunity. Em James Garbarino (Ed.), Children and families in the social environment. (2nd ed.) (pp. 3570).New York: Aldine de Gruyter,

Garmezy, N.(1991) Resiliency and vulnerability to adverse developmental outcomes associated with poverty. American Behavioral Scientist, 34, 416-430.

Grotberg, E. (1995) A guide to promoting resilience in children: strengthening the human spirit. The Hague: The Bernard van Leer Foundation.

Hawley, D. R. \& DeHann, L. (1996) Toward a definition of family resilience: integrating life span and family perspectives. Family Process, 35, 283-298.

Longman Dictionary of Contemporary English (1995). (3a ed.) Longman Dictionaries.

Luthar, S. S.; Cicchetti, D. \& Becker, B. (2000) The construct of resilience: a critical evaluation and guidelines for future work. Child Development, 71, (3), 543-562. 
Martineau, S. (1999) Rewriting resilience: a critical discourse analysis of childhood resilience and the politics of teaching resilience to "kids at risk". Tese de Doutorado, The University of British Columbia.

Masten, A. S. (2001). Ordinary magic: resilience processes in development. American Psychologist, 56 (3), 227-238.

Masten, A. S. \& Garmezy, N. (1985) Risk, vulnerability and protective factors in developmental psychopathology. Em Lahey. B. B.\& Kazdin, A. E. Advances in clinical child psychology 8 (pp.1-52) New York: Plenum Press,.

McCubbin, H. I. \& McCubbin, M. A. (1988) Typologies of resilient families: emerging roles of social class and ethnicity. Family Relations, 37, 247-254.

Rutter, M. (1970) Sex differences in children's response to family stress. Em: Anthony, E. J.; Koupernik, C. (Eds.). The child in his family. (pp. 165-196) New York: Wiley.

Rutter, M. (1971) Parent-child separation: psychological effects on the children. Journal of Child Psychology and Psychiatry, 12, 233-260.

Rutter, M. (1979) Changing youth in a changing society: patterns of adolescent development and disorder. London: Nulfield Provincial Hospitals Trust.

Rutter, M. (1981a) Maternal deprivation reassessed. Harmondsworth: Penguin.

Rutter, M. (1981b) Stress, coping and development: some issues and some questions. Journal of Child Psychology \& Psychiatry, 22, 323-356.

Rutter, M. (1985) Resilience in the face of adversity: protective factors and resistance to psychiatric disorder. British Journal of Psychiatry, 147, 598-611.

Rutter, M. (1987) Psychosocial resilience and protective mechanisms. American Journal of Orthopsychiatry, 57, (3), 316-331.

Rutter, M. (1993) Resilience: some conceptual considerations. Journal of Adolescent Health, 14, 626-631.

Rutter, M. (1999) Resilience concepts and findings: implications for family therapy. Journal of Family Therapy, 21, 119-144.

Sheldon, K. M. \& King, L. (2001). Why positive psychology is necessary._American Psychologist, 56 (3), 216-217.

Silva Jr., J. F. (1972) Resistência dos materiais. São Paulo: Ao Livro Técnico.

Sroufer L. A.\& Rutter, M. (1984) The domain of developmental psychopathology. Child Development, 55, 17-29.

Tavares, J. (2001). A resiliência na sociedade emergente. Em Tavares J. (Org.) Resiliência e educação, (pp. 43-75). São Paulo: Cortez.
Timosheibo, S. P. (1983) History of strength of materials. Stanford.

Walsh, F. (1993) Conceptualization of normal family processes. Em: Walsh, F. (Ed.). Normal family processes. (pp. 3-69), New York: The Guilford Press,.

Walsh, F. (1996) The concept of family resilience: Crisis and challenge. Family Process, 35, 261-281.

Walsh, F. (1998) Strengthening family resilience. New York; London: The Guilford Press.

Walsh, F. (1999) Spiritual resources in family therapy. New York/ London: The Guilford Press.

Werner, E. E. (1986) The concept of risk from a developmental perspective. Em: Keogh, B. K. (Ed.). Advances in special education, developmental problems in infancy and preschool years, V.4 (pp. 1-23) Greenwich, Conn.: JAI Press.

Werner, E. E. (1993) Risk, resilience and recovery: perspectives from the Kauai longitudinal study. Development and Psychopathology, 5, 503-515.

Werner E. E.\& Smith, R. S. (1982) Vulnerable but invincible: a longitudinal study of resilient children and youth. New York: McGraw-Hill,.

Werner E. E.\& Smith, R. S. (1989) Vulnerable but invincible: a longitudinal study of resilient children and youth. New York: Adams-Banaster-Cox.

Werner E. E.\& Smith, R. S. (1992) Overcoming the odds: highrisk children from birth to adulthood. Ithaca/London: Cornell University Press.

Yunes, M. A. M. (2001) A questão triplamente controvertida da resiliência em famílias de baixa renda. Tese de Doutorado, Pontifícia Universidade Católica de São Paulo, São Paulo.

Yunes, M. A. M. \& Szymanski, H. (2001). Resiliência: noção, conceitos afins e considerações críticas. Em: Tavares J. (Org.) Resiliência e Educação, (pp. 13-42). São Paulo: Cortez.

Zimmerman, M. A.\& Arunkumar, R. (1994) .Resiliency research: implications for schools and policy. Social Policy Report: Society for Research in Child Development, 8 (4), $1-18$. 